\title{
From Cash to Cashless Economy: Catalytic Agent for Financial Inclusion?
}

\author{
Megha Jain* and Aishwarya Nagpal**
}

\begin{abstract}
The announcement by Prime Minister Narendra Modi on July 1, 2015 towards "making India Digital" was meant to pave Indian economy's future for larger proposed changes in terms of financial literacy. The drive intended to associate pastoral areas with highspeed internet so as to improve the digital awareness and usage. Thereafter, the catalytic thrust from demonetisation further accelerated migration towards digital payments in November and December 2016. However, ease in availability of cash by gradual remonetisation jolted the pace of growth of digitalisation in February 2017. In this context, the future outlook of Indian economy guarantees fast-track growth that carries preliminary pre-requisite for the people to be financial literate, to begin with. Thus, 'Digital financial literacy' shall require more strengthening. This paper spots the rationale and sequencing of the targeted drives to facilitate building on the 'financial literacy infrastructure' principally to benchmark future India. The key policy implication of the current study includes the solution to the dilemma and apt targeting of the various programmes for financial stability and sustainability through 'Digitally Literate Future'.

Keywords: Indian economy; Financial inclusion; Digitisation; Demonetisation; Digital financial literacy.
\end{abstract}

\subsection{Introduction}

Prime Minister Narendra Modi declared the demonetisation decision on November 8, 2016 to extract 86 per cent of the currency in circulation by withdrawing the legal tender of two highest denomination currency notes (INR 1000 and INR 500). While the Government's demonetisation decision was highly debated, a crucial point which went largely missing was that India is not the only country in the rising anti-cash movement and creation of digital economy across the world.

\footnotetext{
*Corresponding author; Research Scholar, Faculty of Management Studies, University of Delhi, Delhi, India. (Email id: megha.j_phd15@fms.edu)

** Research Scholar, Faculty of Management Studies, University of Delhi, Delhi, India.

(Email id: aishwarya.n_phd15@fms.edu)
} 
Two major initiatives of India's collaboration at global terrain went greatly unnoticed. In September 2015, India joined the UN 'Better than Cash Alliance', an implementing partner for G20 Global Partnership for Financial Inclusion, and the Ministry of Finance consorted with the USAID ${ }^{1}$ towards cultivating a digitally inclusive economy. From an economic stance, demonetisation has delivered a strong thrust for digital transactions, which is envisaged to uplift consumption, boost aggregate demand and enlarge the tax net. However, the underlying thrust for this transformation from 'Demonetisation drive' to 'Digital India campaigns' remains questionable from the much talked about 'Financial Inclusion' perspective. The same has been debated on several platforms for aspects like its effective management (implementation and design) along with short-medium run economic impact and future conduct of economic policy ${ }^{2}$. The forum questions much of the 'Inclusive finance' on 'Digital literacy financial inclusion'. One obvious imminent challenge based on this - Does India's 'targeted ordering ${ }^{3}$ hold appropriate?

Financial Inclusion is not limited to just universal gateways to range of financial services at minuscule cost any more. The scope is redefined in its own unique way backed by the above two path-breaking steps by the Indian government. However, the adequacy of the same is largely debated among the policy think-tanks. The rising disparities among the rural and urban national (confirmed by rising Gini coefficient to 0.28 in rural areas and 0.37 in urban areas in 2011-12) for credit access opportunities (micro finance) needs a detailed investigation.

India's demonetisation move has uncovered the blunt of digital financial subdivide of the nation. The current exposure towards Electronic Financial Literacy (a new branch of financial literacy stemming out of the Demonetisation drive) reveals that India has a long travel to go before it is fully recognised as a digital financial economy. As per OECD (2005), financial literacy is an amalgamation of knowledge, attitude, financial awareness, skills and behaviour; vital to make sound financial decisions and eventually facilitate financial well-being of every individual. Based on the same notion, electronic financial literacy would combine the skills, attitudes and behaviours essential to converge to apt financial decisions electronically. Hence, demonetisation and digitisation underlines an important question, is India electronically financially literate? The dilemma is that country's official literacy rate is 74 percent, and this chiefly comprises people who can barely sign their names.

With this background, the current study aims to examine the impact and prospects of the referred campaigns towards financial inclusion through digital financial literacy. The scheme of the study is as follows. Section 2 discusses the existing review of literature to examine the digital financial inclusion as a priori to financial inclusion. 
42 MUDRA: Journal of Finance and Accounting, Volume 4, Issue 1, Jan-Jun 2017

Section 3 briefly discusses the rationale/ need for the historic moves along with the relevance of financial inclusion. Section 4 entails critics of the discussed drives towards inclusion and literacy. Finally, Section 5 concludes the study from a broad policy perspective.

\subsection{Review of Literature}

There are several studies so far that highlight the prerequisite of digitisation before financial inclusion and existence of marginal literature on digital financial literacy strengthening. The same enables to identify the research gap that the current study is discussing in detail in the later sections. A study by Jani and Tere (2015) analyses the availability of various services on demand by the Indian citizens. It further confirms the need for infrastructural support especially IT enabled facilitation through campaign like digitisation to make it accessible to each and every person. They have emphasized IT facilitation as an indispensable tool towards financial inclusion. A similar study by Sharma and Kukreja (2013) lays down comparison between India and rest of the world (ROW) on financial inclusion (including the banking sector) based on the survey report by World Bank. The authors have concluded with suggestion for much needed improvements to go a long way before Indian economy achieves the respectable level of financial inclusion.

The above is additionally supplemented by Tamilarasu (2014) who has examined the banking sector importance in financial inclusion for an economy like India. He has observed that over a period of time, officers' strength is diminishing substantially in commercial banks and conversely, an increasing trend in the number of commercial bank branches between 2008 and 2013. Further, Morgan and Pontines (2014) has reassessed the association between financial stability and inclusion to identify their mutual reinforcement or trade-off between them. Diversification of bank assets, reducing riskiness, increased stability are positive points and erosion of credit standards, bank reputation risk, inadequate regulation of MFI's are the negative points according to his study.

Besides the above, there is significant literature that exists on the optimum usage of payment technologies. The same are cited based on international as well as Indian studies. Since the poor often encounter high transaction costs, IT innovations can enable to reduce the same to promote inclusion. There is an ample evidence that supports the positive impact of digital payments technologies. As per study by Jack, Ray and Suri (2013); Jack and Suri (2014), the M-PESA scheme in Kenya is considered a progressive step towards promotion of digital usage of e-payment modes to facilitate inclusion where 
consumption patterns are made smoother by incremental usage of frequent and longer distance money transfers. Additionally, as per study by Mas and Morawczynski (2009); Medhi et al. (2009), the success of digital financial campaigns largely depends on several prerequisites where infrastructure, regulatory policies, and details of user interface design play a key role.

India specific-studies indicate that digital payments have now been theorized as one of the key elements of a three-part approach for financial inclusion using digital enabling technologies: JAM, standing for Jan Dhan (banking), Aadhaar (identity) and Mobile (transactions). The studies by Banerjee et al. (2016); Muralidharan et al. (2016) and Imbert and Papp (2015) shed light on the role of biometric identity cards (Aadhaar) in reducing corruption to promote welfare programs, and economize on expenditures. Also in the study by Ravi and Gakhar (2015), there is much broader scope of financial services defined to link digital innovation so as to take benefits from economies of scope provided the fixed costs of infrastructure and adoption. Other evidence of positive influences include Afghanistan (Blumenstock et al., 2015) and Nigeria (Aker et al., 2014) from using digital technologies that suggest on the replicable opportunities for thriving innovations.

A study by Lusardi and Mitchell (2014) provides a brief account of theoretical and empirical (mainly from industrial countries) issues encircling financial literacy. One common fundamental problem faced by all countries is lack of sufficient information (Gine et al., 2014, for Mexico). Miller et al. (2014) has examined assessment of 188 financial education programs and discovered weak evidence for positive effects on financial know-how. However, teaching simplified guidelines for behavior as rules-ofthumb seem to have a positive impact (Drexler et al., 2014).

CRISIL (2013) has measured the magnitude of financial inclusion in India in the form of an index. It has mainly considered the non-financial aggregates for computing financial inclusion. The key decisions of the report are as follows: one in two Indians has a savings account and only one in seven Indians has access to banking credit; CRISIL inclusix at an all-India level stands at a relatively low level of 40.1 for 2011 (on a scale of 100). Thus, CRISIL has given base-level information regarding the advances of financial inclusion in the country's rural and urban areas. Kamath (2008) has made an attempt to understand the impact of Micro-Finance Institution (MFI) loans on daily household cash flows by analyzing cash inflow and outflow patterns of borrowers of MFI and comparing with non-MFI households.

A study by Aggarwal and Klepper (2013) stresses on how government policy interventions can alleviate bottlenecks to financial inclusion specifically with respect to savings, payments and financial literacy. They have drawn on a range of sources of 
evidence while assessing what can or may work. Resonating Karlan and Morduch (2010), they have cited that "policy-design must be tailored to the systemic failure in each setting for financial inclusion efforts to be successful". For example, they have suggested remote rural population benefits' may come by conquering distance barriers whereas the urban poor can be relieved with lesser documentation obligations. One such preliminary study by Kumar (2007) has investigated and laid down that the financial inclusion can't be erstwhile activity rather it is a continuing process. He mainly has concentrated on the banking sector to analyse the above. He has further urged for united efforts from all stakeholders, society, law makers, financial institutions, government, community etc. He has underlined the criticality of IT in financial inclusion. He has purported the role of technology to play a key role to determine the level of financial inclusion.

\subsection{Rationale}

Demonetisation is fast-tracking a process of digitisation across the economy that would have otherwise taken years to reach culmination. The main thrust of the demonetisation drive is to accelerate the growth transformations via digital economy. This shall eventually lessen the cash pertinence and transit with least cost to primarily a cashless (digital) economy. It transmits bi-effect of positive(s) and negative(s), though this transition imperatively is not going to be linear. Additionally, the effects are not expected to be pervasive especially for the unorganised sector of the economy where buyers and suppliers still mainly rely on cash payments. Figure 1 entails the aggregate usage in value (in Rs. billion) and volume (in million) of Electronic Payment Systems (EPS) from Nov-16 to June-17.

\section{Figure 1: EPS (Electronic Payment System) transactions monthly comparison}

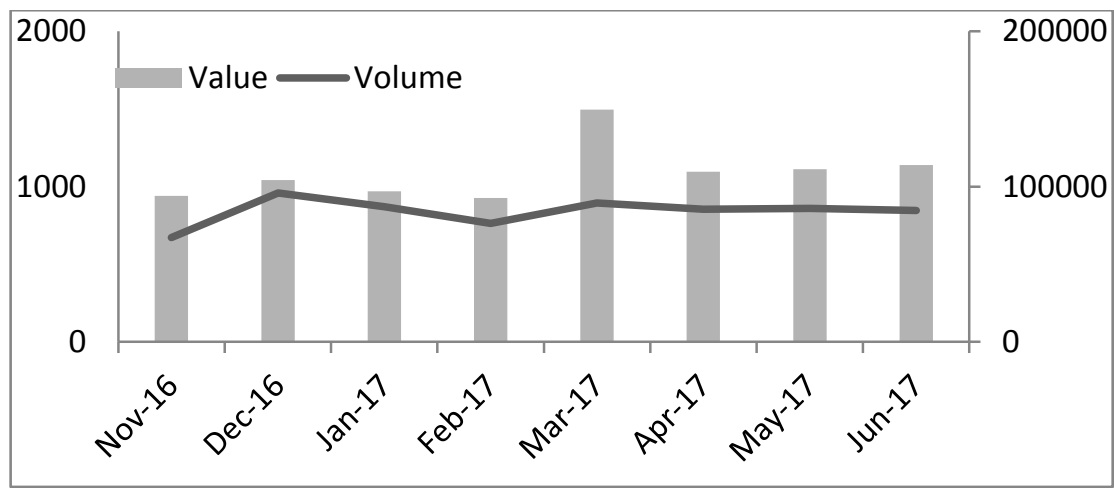

Source: Authors' representation from data sourced from NPCI. 
Figure 1 clearly indicates the moderation in both value and volume usage of electronic medium in Q1, FY 2017-18 (post-demonetisation) over Q3 (demonetisation phase) and Q4, FY 2016-17. Digitisation, the elementary pillar of financial inclusion (for greater access) needs to be re-checked for the underlying reasons of moderation in the latter half for the electronic mode of transactions. Due to infusion of more digital mediums like PoS machines, the digital data footprint of individual SMEs in India previously non-existent or obscured by the parallel cash economy - will transpire to greater transparency. And as SMEs become proficient at electronic payment systems, they will join the formal economy; to prompt, cash-less-ness and the use of digital technology. However, Figure 2 provides the contrasting change over stance from Nov-16 to June-17 for usage of different EPS modes.

Figure 2: EPS composition from Nov-16 to Jun-17 (during and post demonetisation)

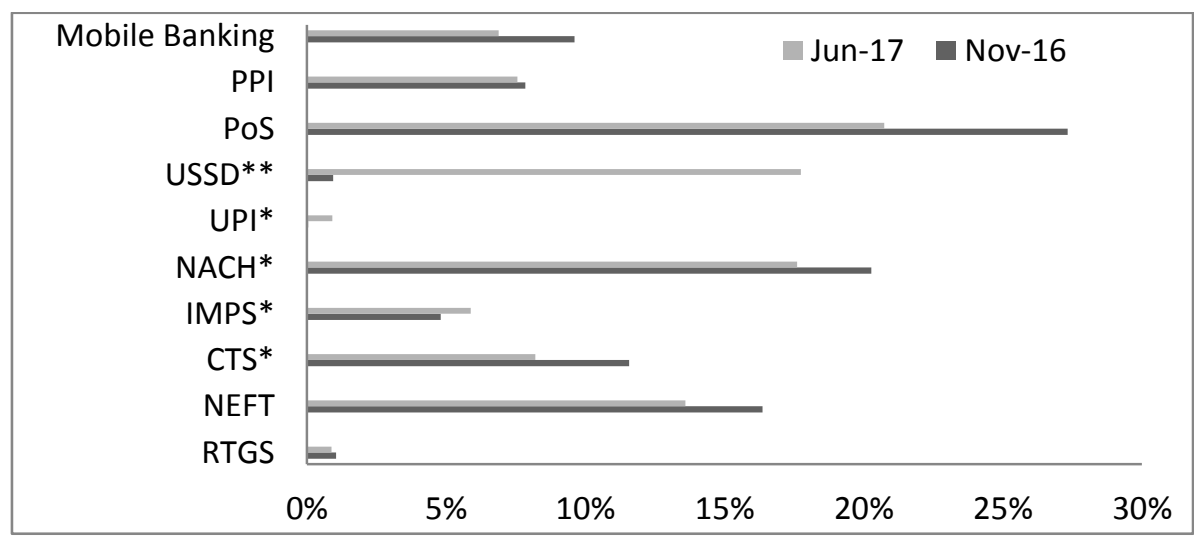

Source: Authors' representation from data sourced from NPCI.

Notes: CTS: Cheque Truncation System, USSD: Unstructured Supplementary Service Data, UPI: Unified Payments Interface, NACH: National Automated Clearing House IMPS - Immediate Payment Service

It is quite apparent from Figure 2 that the composition of EPS medium is declining from Nov-16 to Jun-17 for most of the mediums indicated above. The same hints towards the temporary increase in the aggregate electronic digital activities during demonetisation due to the paucity of alternatives available that time. Financial inclusion could be placed effectively only with permanent initiatives that could be sustained for long. Surprisingly, only $15 \%$ of the point of sale (PoS) transactions take place using credit or debit cards. This compares with the $88 \%$ that use cards to withdraw cash at 
ATMs. Figure 3 entails the inter country comparison of usage of physical currency in value and volume (in \%). The above graph clearly ranks India as the $2^{\text {nd }}$ highest after Indonesia in comparison to USA, UK, Japan, South Africa, China etc. for its relative higher reliance on 'cash' as the common medium of economic transactions. Alarmingly, India holds the highest cash to GDP ratios globally. Apart from an obliviously unaware lot, there is another set of the population who deliberately avoid digitalization in order to not leave a trail of such transactions. This compositely hints towards the burden of an over-bearing cash economy and beseeching need to turn around with financial inclusion strengthening and digitisation empowerment.

Figure 3: Inter Country Comparison of Cash Transaction in 2015

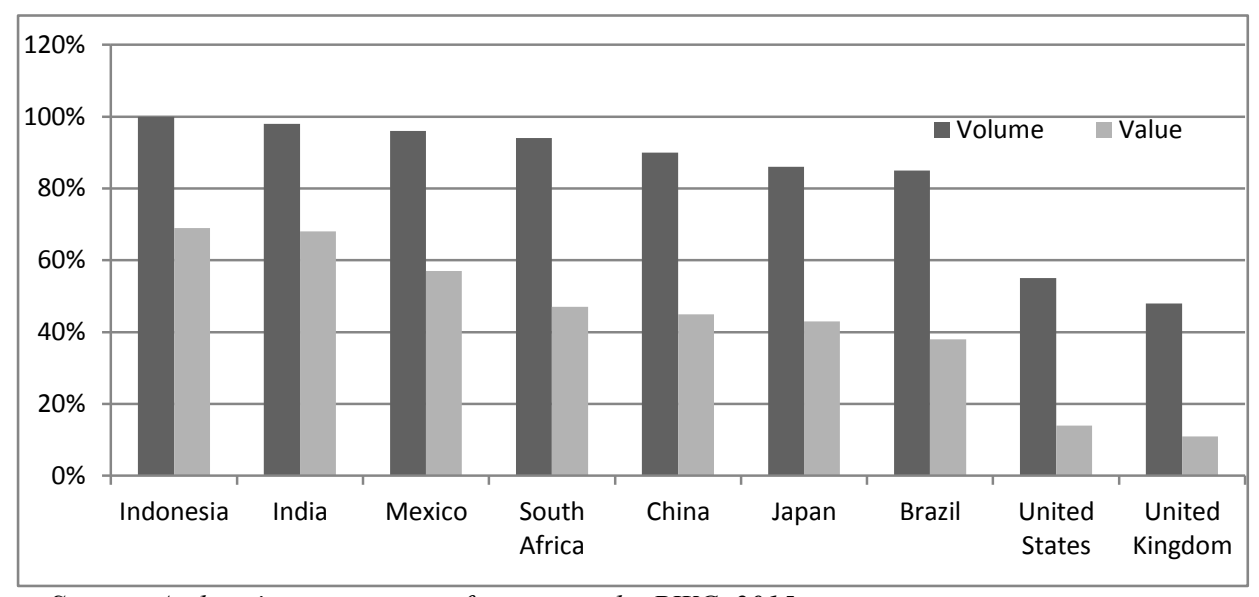

Source: Authors' representation from report by PWC, 2015

\subsection{Impact: A Critique}

Demonetisation has impacted every niche in India. To start with, business structures have hinted a change. Due to demonetisation, India is making the move from a cash based economy to a cashless economy. Secondly, GDP and tax collection have brighter prospects due to increase in tax collections by widening the tax base. The same in turn would facilitate governmental increase spending in essential sectors, thus having a ripple effect through spending multiplier to influence the standard of living of the underprivileged. This may prove to be a future welcoming step towards 'financial inclusion'. At the same time, the whole thrust of inclusion to make easy availability of the financial access 'opportunities to all', seems to fail heavily. Many of the surveys ${ }^{4}$ 
supported the severe hit of demonetisation on poor, the farmers and the citizens employed in the informal sector the most.

Also, most of the developed nations are digitised and put high reliance on plastic currency and smart cards. Additionally, in the case of India, the preliminary stage of plastic money has been completely skipped and the economy moved from paper money to digital wallets. Though, as per provisional data from the Reserve Bank of India (RBI), April-17 has witnessed total digital transactions of Rs 109.58 trillion, down by $26.78 \%$ from Rs 149.58 trillion in March-17. Debit and credit card usage in April-17 at PoS machines also have declined by around 3.5\% to 221.5 million transactions from 229.7 million in the previous month (RBI database).

Table 1 are the key measures implemented by the Government to endorse digital and cashless economy. These measures are to benchmark Indian economy at par with global standards and to contain the economic offences like tax evasion, money laundering etc. Howver, the efficacy and adequacy remain largely debatable. The recent GCI rankings of India for FY 2016-17 on technological readiness and financial market development confirm just the converse.

Table 1: Key Measures Announced by the Government for 'Digital India' Campaign

\begin{tabular}{|c|c|}
\hline Post Demonetisation & Budget 2017-18 \\
\hline $\begin{array}{l}\text { - Discount of } 0.75 \text { per cent for making } \\
\text { digital payments for purchase of } \\
\text { petrol/diesel }\end{array}$ & $\begin{array}{l}\text { - Ban on cash transactions beyond INR } 0.3 \\
\text { million threshold }\end{array}$ \\
\hline $\begin{array}{l}\text { Discount of } 0.5 \text { per cent and free } \\
\text { insurance cover for buying rail tickets } \\
\text { online }\end{array}$ & $\begin{array}{l}\text { - Incentive schemes to promote BHIM App } \\
\text { - Referral Bonus for individuals \& Cash } \\
\text { back scheme for merchants }\end{array}$ \\
\hline $\begin{array}{l}\text { - Financial support through NABARD } \\
\text { to banks for deployment of PoS } \\
\text { devices in less populated rural areas }\end{array}$ & $\begin{array}{l}\text { - Aadhaar Pay for merchants to be } \\
\text { launched shortly }\end{array}$ \\
\hline - Issuance of Rupay Kisan Cards & $\begin{array}{l}\text { - Allocation of BharatNet project increased } \\
\text { to } 100 \mathrm{bn}\end{array}$ \\
\hline $\begin{array}{l}\text { - Discounts for online purchase of } \\
\text { general insurance policies from } \\
\text { national insurers }\end{array}$ & $\begin{array}{l}\text { Presumptive income tax benefit for small } \\
\text { and medium tax payers }\end{array}$ \\
\hline $\begin{array}{l}\text { Limiting monthly rental of PoS } \\
\text { terminals for merchants to INR } 100 \\
\text { by public sector banks }\end{array}$ & $\begin{array}{l}\text { - Tax exemption on manufacturing of } \\
\text { devices for cashless transactions }\end{array}$ \\
\hline $\begin{array}{l}\text { - Removal of Service tax on digital } \\
\text { transactions upto INR } 2000 \text { per } \\
\text { transaction }\end{array}$ & $\begin{array}{l}\text { Duty-free imports allowed of point-of- } \\
\text { sale and other digital authentication } \\
\text { equipment }\end{array}$ \\
\hline
\end{tabular}


48 | MUDRA: Journal of Finance and Accounting, Volume 4, Issue 1, Jan-Jun 2017

Figures $4 \mathrm{~A}$ and $4 \mathrm{~B}$ indicate the comparison of $8^{\text {th }}$ and $9^{\text {th }}$ pillar of Global Competitiveness Index (GCI) for India from 2012-13 to 2016-17. The same is highlighted for ease of access to loans and venture capital availability under Pillar-8 along with internet users (\% population) and internet bandwidth under Pillar-9 over the years. Table 1 includes all the major announcements that the Government of India (GOI) has made post-demonetisation and during budget to enable smooth digital transition and competitiveness.

\section{Figure 4A: GCI Pillar-8 (Financial Market Development) Values and Ranks for India}
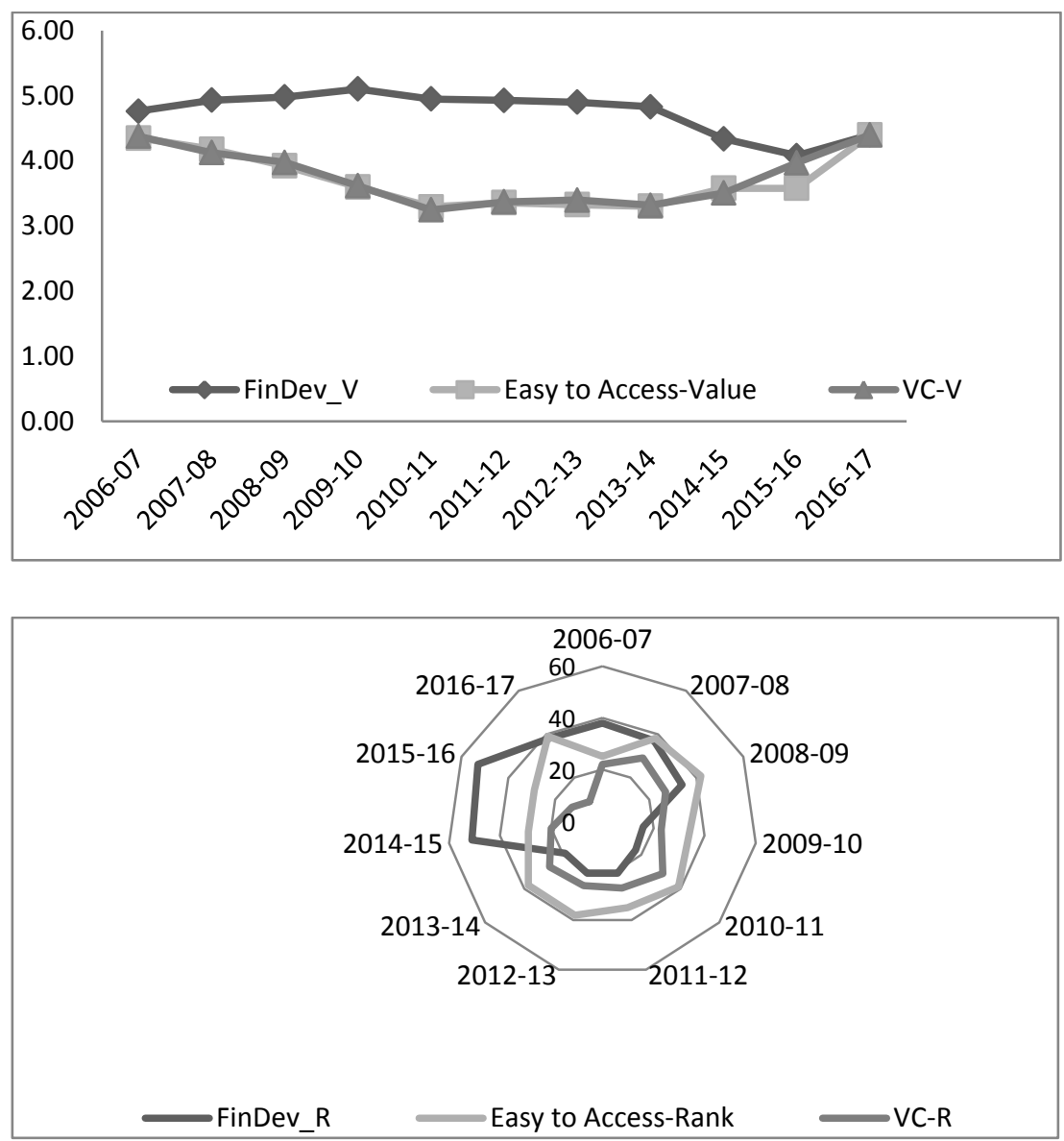

Source: Authors' representation from GCI database, World Economic Forum Notes: GCI values range from 1 to 7 where 1 represents the worse and 7 the best. GCI ranks are given to order position for 144 countries. 
Figure 4A (line and radar graph) represent the GCI $8^{\text {th }}$ pillar value and rank for India from 2006-07 to 2016-17. The financial development values have marginally progressed overall with marginal changes in easy to access loans and venture capital availability from 2006-07 to 2016-17. The radar chart clearly validates the lack of inclusiveness impact of financial moves in the wake of demonetisation and digitisation as the ranking has deteriorated by 10 places in $2016-17$ to 39 over $29^{\text {th }}$ place in $2015-16$.

\section{Figure 4B: GCI Pillar-9 (Technological Readiness) Values and Ranks for India}
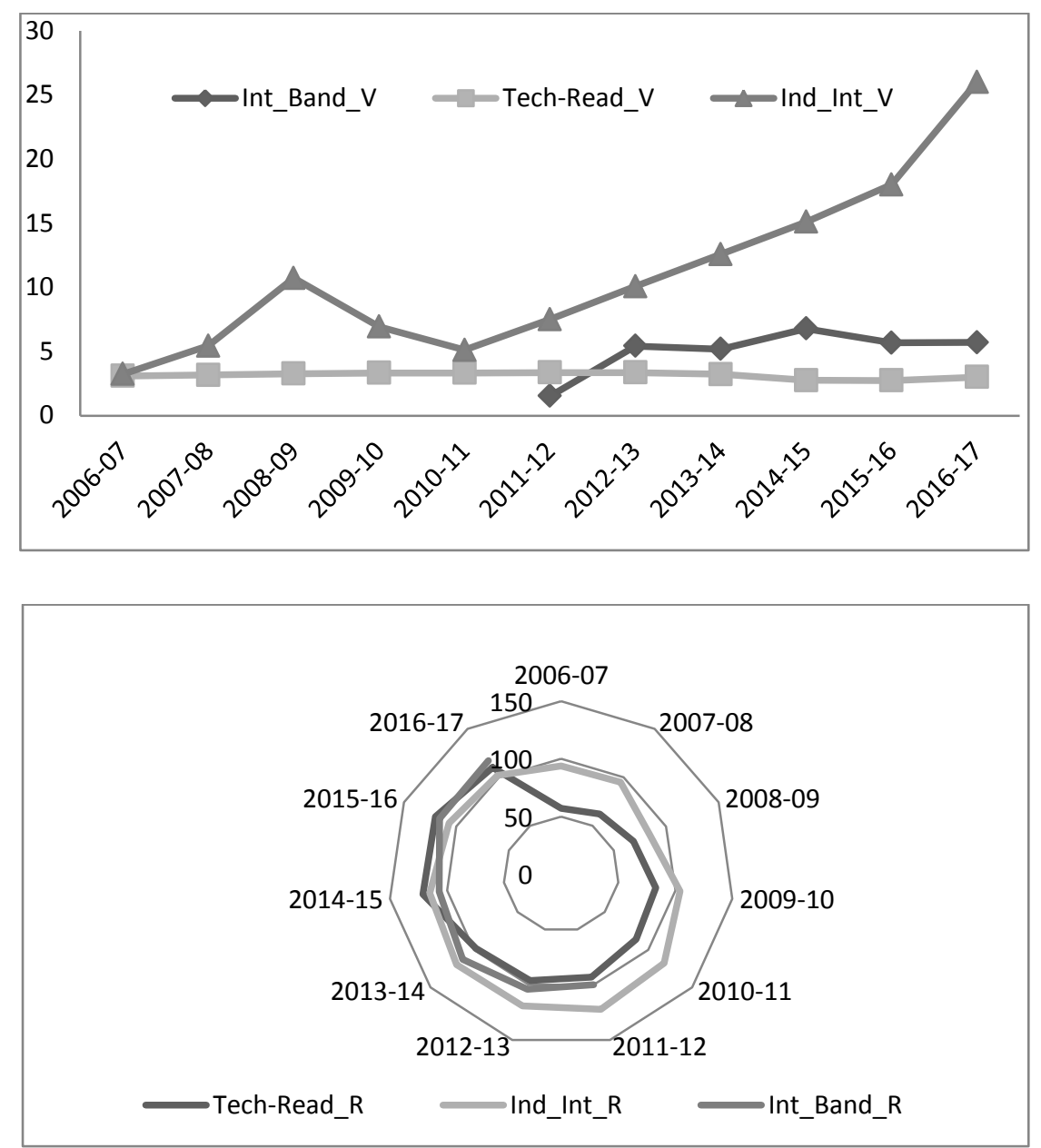

Source: Authors' representation from GCI database, World Economic Forum Notes: GCI values range from 1 to 7 where 1 represents the worse and 7 the best. GCI ranks are given to order position for 144 countries. 
Figure 4B represents that the GCI score of technological readiness has moderated after the drop from 2014-15 for India on Pillar-9. The rankings for internet bandwidth (the technological infrastructure) have performed worse in 2016-17, 2015-16 over 2014-15. The technological readiness rankings have crossed $100^{\text {th }}$ position post $2013-14,98^{\text {th }}$ position. The above indicates the lack of preparedness and required set-up that serve pre-requisite for campaigns like demonetisation and digitisation before these truly signify financial inclusion.

We now compare the lacuna from the demand and supply side sufficiency.

- On the demand side, digital financial literacy is a significant factor in shaping financial inclusion.

- On the supply side, sufficient digital gateways are already announced under einitiatives by the Indian government to promote digitisation.

However in the present scenario, there is a situation of imbalance in the economy as supply has not been able to cope up with demand. There are a variety of issues surrounding digital financial literacy, the major being the challenges of educating consumers of online financial services. For a country like India, electronic financial literacy plays a key role as it is considered an essential adjunct to promotion of financial inclusion, specifically after the demonetisation phase and ultimately financial stability. One basic problem India passing through is the lack of information, and also how information asymmetries are overcome can be crucial. Table 2 and Figure 5 below give an overview on India's standing vis-à-vis other nations on Financial Literacy key elements and level of financial literacy. They reflect some of the stark statistics. According to a global survey by Standard \& Poor's Financial Services LLC (S\&P) ${ }^{5}$, less than $25 \%$ of adults are financially literate in South Asian countries. For an average Indian, financial literacy is yet to become a prime motive.

Table 2: Financial Literacy Composition

\begin{tabular}{|l|c|c|c|c|}
\hline Components & India & BRICS & $\begin{array}{l}\text { South Asia } \\
\text { excluding India }\end{array}$ & World \\
\hline Risk Diversification & 14 & 28 & 18 & 35 \\
\hline Inflation & 56 & 46 & 46 & 50 \\
\hline Interest & 48 & 48 & 46 & 49 \\
\hline Compound Interest & 44 & 44 & 39 & 45 \\
\hline Financial Literacy (\%) & $\mathbf{2 4}$ & $\mathbf{2 8}$ & $\mathbf{2 3}$ \\
\hline
\end{tabular}


Figure 5: Financial Literacy Rate

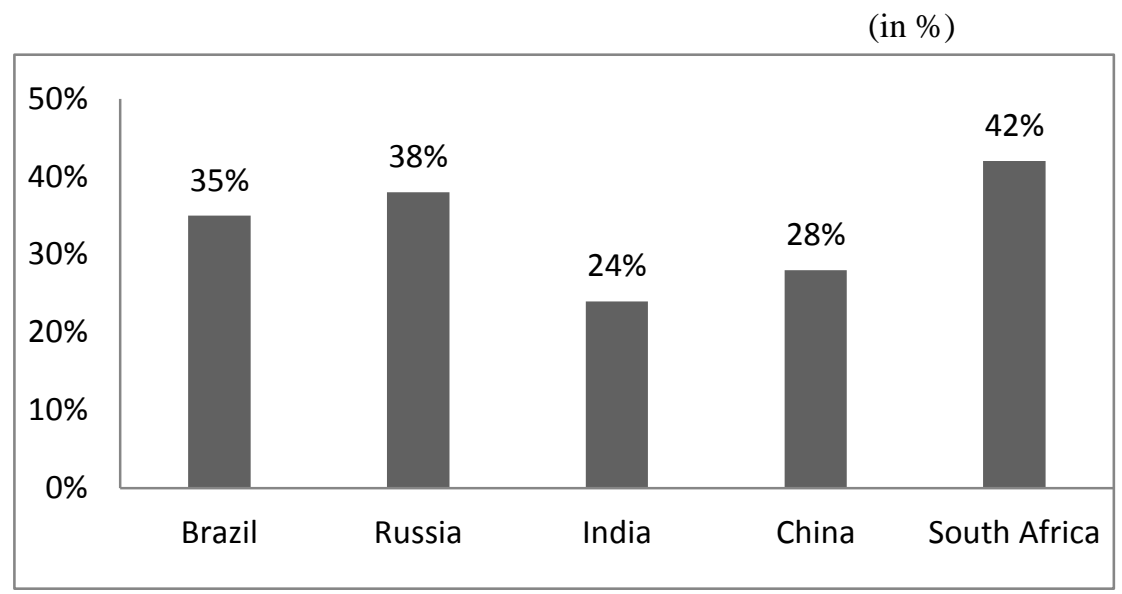

Source: S\&P Global Financial Literacy Survey

(Available at at http://gflec.org/initiatives/sp-global-finlit-survey/)

India is home to $17.5 \%$ of the world's population but approximately $76 \%$ of its adult population does not fathom even the basic financial concepts. The survey reaffirms that financial literacy in India has unfailingly been poor compared to the rest of the world, as is evident from the above Fig-4. Financial illiteracy definitely places a burden on the nation in the form of higher cost of financial security and lesser prosperity.

\subsection{Indian sectoral compositional irony}

The recent gigantic exercise of demonetisation should help bring many more people under the umbrella of organised sector, thereby opening up prospects for financial inclusion and financial literacy. While articulating about financial inclusion in India, we only take into account two categories of people: those have a bank account and those who don't. India's sizeable informal economic sector (consisting of domestic help, daily wage workers, farmers, fishermen, contract labourers, micro entrepreneurs, etc.) is outside "the ambit of formal banking" and runs virtually wholly on cash. This category of people usually does not have a formal bank account or adequate identification documents.

As per a report produced by PwC India ${ }^{6}$ (2015), it is discovered that India's unbanked population during that year is at 233 million. This is approximately half the number it is in 2011, at 557 million, predominantly because of the Pradhan Mantri Jan Dhan Yojana scheme targeted at making it convenient for people to open new accounts. Since then, the Jan Dhan Yojana has grown even more, adding 68 million accounts by 
2016, but that still leaves about 165 million people unbanked. A considerable 23 percent of these accounts still remain inactive, signifying that it will take a lot more than merely opening formal bank accounts for the financially excluded to be truly included. Figure 6 portrays a comparison of India with other nations in terms of the unbanked population. The same are based on the recent survey by PwC on Financial Literacy.

Figure 6: Population (in Millions) in 2015

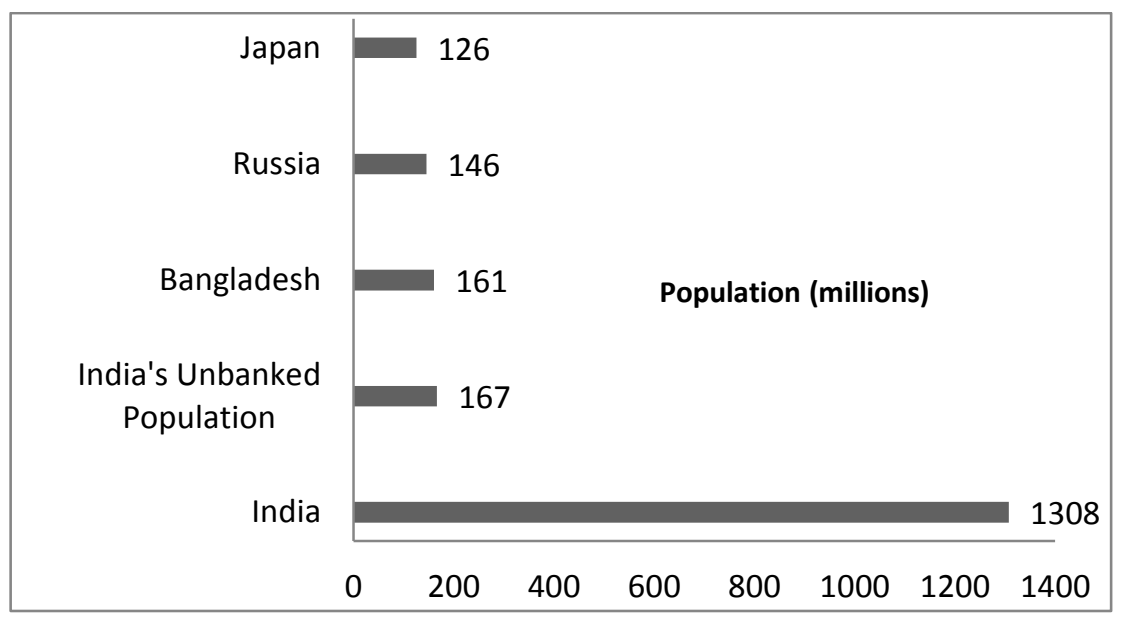

Source: $P w C, R B I, P M J D Y$

Figure 6 is conclusive of the fact that if the entire unbanked population in India were a country, it would be the world's eighth largest country - more populous than even Bangladesh. However, given the escalation of digital financial services in the last couple of years, and the acceleration of financial access through copious electronic platforms, financial inclusion is being perceived through a new vision: 'those who are digitally financially included' versus 'those who are not'.

\subsection{Conclusion}

The major question arises here is: 'Will demonetisation clubbed with digitisation pave the way for India's financial inclusion landscape?' The massive demonetisation exercise will not bring the naive to digital financial platforms instantaneously. At present, cash is a prerequisite for the majority of people both in rural and urban areas of India to get by in life. The fact that e-wallet companies have witnessed a prompt surge in the quantum of transactions and traffic on their web and app-based platforms after the 
high-impact demonetisation phase definitely holds true, but it cannot be denied as well that these are mostly compelled by urban and metropolitan parts of the country. The set of circumstances since the demonetisation announcement surely must have taken people further away from holistic financial inclusion, toppling their financial and overall wellbeing, and shaking their trust in financial institutions and the government.

In spite of this dramatic step, the instance for digital money and digital financial services has never been firmer. Pointless to say, many pedals in the system need to function simultaneously for us to achieve this scenario, including infrastructure, better internet connectivity, more value added services, regulatory support, removing blockades in penetration of payment technology and most significantly digital financial literacy, i.e, handholding of fresh users to bring in behavioural transition. With such depressing figures of financial inclusion and literacy, both of which are a precondition for a digital economy, a cashless economy cannot materialise overnight. In order it to be upright in the long run, financial literacy remains pivotal (Figure 7).

Figure 7: Proposed Framework that needs strengthening

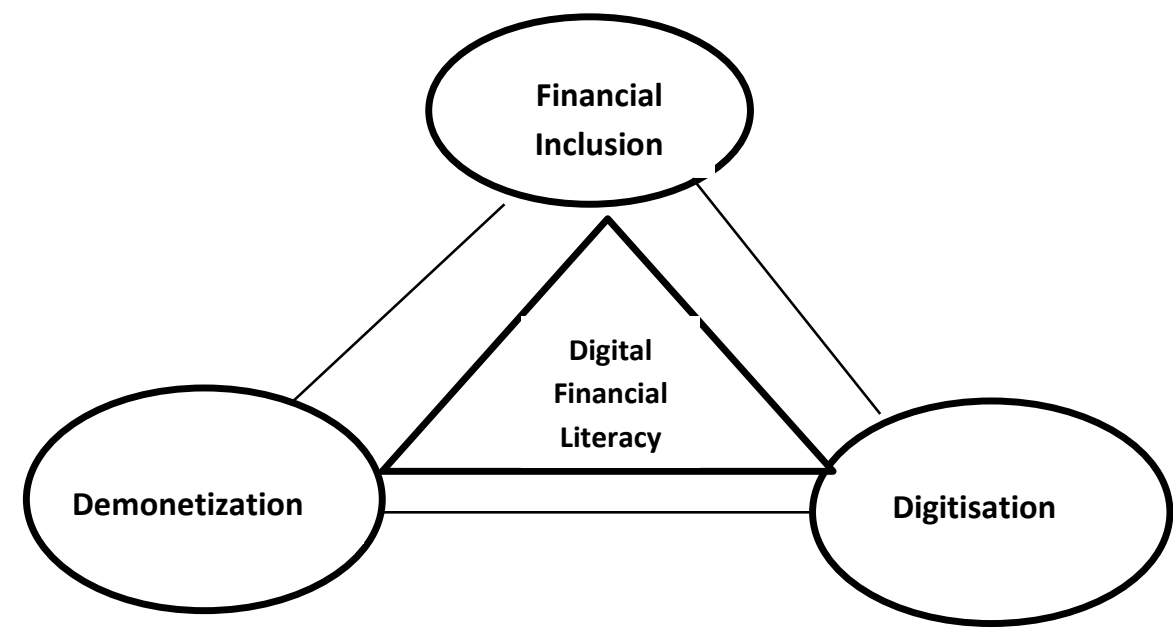

Source: Author's own design

Financial literacy and financial stability are two vital facets of an efficient economy. Financial literacy boosts individuals' ability to guarantee economic security for their families. It emphasizes on the understanding one should have regarding how to use and manage the money efficiently and mitigate the risk and save their money from extraneous changes such as changes in the economy, governmental policies etc. In India, 
54 | MUDRA: Journal of Finance and Accounting, Volume 4, Issue 1, Jan-Jun 2017

on one hand, there is an urgent need to connect to lower income groups and economically feeble sections on the other hand and to millennials who are closely knitted and entail tailor-made financial products on the other hand. The bottom-line, consequently, is that a 'me-too' approach to financial literacy may not work for India.

In the wake of demonetisation and Centre's push to move towards a cashless economy, the government and other stakeholders including consumers should work in conjunction for financial literacy through a combination of innovative strategies and hence must undertake campaigns to educate people on electronic financial literacy. Financially literate digital India must be the spotlight to garner, proposed long term gain. The digital economy can be intensely leveraged to disseminate financial literacy.

Financial literacy through the use of technology needs to be based on three key principles:

- First, to effectively use the power of mediums like a computer, mobile and Internet;

- Second, to facilitate people to have the skills, knowledge or information about financial instruments, and;

- Third, it must be warranted people then have the capability to analytically comprehend the content they have received through digital means and lastly administer it to the best of their knowledge and capacity.

However, for financial education to genuinely serve its intent, partnerships should be established among all stakeholders including those formulating the policies and those functioning at the grassroots level. Thus, the responsibility lies with everyone to actively participate in augmenting financial literacy levels for the good of investors and a greater good of the society.

\section{Endnotes}

1. Available at www.bmradvisors.com/download.php?resourceId=1610.

2. From 'Demonetisation: To Deify or Demonize?' by Paramahamsa and Middlemarch, Economic Survey 2016-17.

3. Targeted ordering refers to moving from 'Financial inclusion to digitisation to demonetisation to financial literacy'.

4. Available at https://thelogicalindian.com/awareness/demonetization/

5. S\&P survey: More than $70 \%$ Indians fare badly in financial literacy. (2014). Available at http://www.livemint.com/Money/219bZsVo7eempRU9yLvPAL/SP-survey-More-than-70Indians-fare-badly-in-financial-li.html

6. Available at https://scroll.in/article/822464/demonetisation-indias-unbanked-populationwould-be-the-worlds-7th-largest-country 


\section{References}

Aggarwal, S., \& Klapper, L. (2013). Designing government policies to expand financial inclusion: Evidence from around the world. Retrieved from http://www.isb.edu/faculty/shilpa_aggarwal/files/shilpa-aggarwal-leora-klapper.pdf.

Aker, J. C., Boumnijel, R., McClelland, A., \& Tierney, N. (2014). Payment mechanisms and anti-poverty programs: Evidence from a mobile money cash transfer experiment in Nigera. Center for Global Development Working Paper 268.

Banerjee, A., Karlan, D., \& Zinman, J. (2015). Six randomized evaluations of microcredit: Introduction and further steps. American Economic Journal: Applied Economics, 7(1), 1-21.

Banerjee, A., Duflo, E., Imbert, C., Mathew, S. \& Pande, R. (2016). Can e-governance reduce capture of public programs? Experimental evidence from a financial reform in India's Employment Guarantee. Retrieved from https://economics.mit.edu/files/10557.

Blumenstock, J. E., Callen, M., Ghani, T., \& Koepke, L. (2015). Promises and pitfalls of mobile money in Afghanistan: Evidence from a randomized control trial. Proceedings of the Seventh International Conference on Information and Communication Technologies and Development, Singapore-May 15-18, 2015.

CRISIL. (2013). Inclusix Financial Inclusion Index. Vol. 1, June.

Drexler, A., Fischer, G. \& Scholar, A. S. (2014). Keeping it simple: Financial literacy and rules of thumb. American Economic Journal: Applied Economics 6(2): 1-31.

Gine, X., C. Cuellar, M. \& Mazer, R. K. (2014). Financial (dis)information: Evidence from an audit study in Mexico. World Bank Policy Research Working Paper 6902.

Imbert, C. \& Papp, J. (2015). Labor market effects of social programs: Evidence from India's employment guarantee. American Economic Journal: Applied Economics, 7(2), 233-263.

Jack, W., \& Suri, T. (2014). Risk sharing and transactions costs: Evidence from Kenya's mobile money revolution. The American Economic Review, 104(1), 183-223. 
56 | MUDRA: Journal of Finance and Accounting, Volume 4, Issue 1, Jan-Jun 2017

Jack, W., Ray, A., \& Suri, T. (2013). Transaction networks: Evidence from mobile money in Kenya. The American Economic Review, 103(3), 356-361.

Jani, J. \& Tere, G. (2015). Digital India: A need of hours", International journal of Advanced Research in Computer Sciences and Software Engineering, 5(8), 318-319.

Kamath, R. (2008). Ramanagaram financial diaries: Loan repayments and cash patterns of the urban slums. IIMB Working paper 268.

Karlan, D. S., \& Morduch, J. (2010). Access to finance. In D. Rodrik and M. R. Rosenzweig (Eds.) Handbook of Development Economics, Volume 5, pp. 4704-4784, Amsterdam: North Holland.

Kumar, N. (2007). Financial inclusion and its determinants: Evidence from India. Journal of Financial Economic Policy, 5(1), 4-19.

Lusardi, A., \& Mitchell, O. S. (2014). The economic importance of financial literacy: Theory and evidence. Journal of Economic Literature, 52(1), 5-44.

Mas, I. \& O. Morawczynski (2009). Designing Mobile Money Services: Lessons from M-PESA. Innovations, Spring, 77-91.

Medhi, I., Gautama, S.N.N. \& Toyama, K. (2009). A comparison of mobile moneytransfer UIs for non-literate and semi-literate users. Proceedings of the SIGCHI Conference on Human Factors in Computing Systems, pp. 1741-1750.

Miller, M., Reichelstein, J., Salas, C., \& Zia, B. (2014). Can You Help Someone Become Financially Capable? A Meta-Analysis of the Literature. Policy Research working paper no. WPS 6745. Washington, DC: World Bank Group.

Morgan, P. J., \& Pontines, V. (2014). Financial stability and financial inclusion. Asian Development Bank Working Paper Series No. 488.

Muralidharan, K., Niehaus, P. \& Sukhtankar, S. (2016). Building state capacity: Evidence from biometric smartcards in India. American Economic Review, 106(10), 2895-2929. 
Ravi, S \& Gakhar, S. (2015). Advancing Financial Inclusion in India beyond the JanDhan Yojana. Brookings India IMPACT Series. Brookings Institution India Center.

Sharma, A. \& Kukreja, S. (2013). An analytical study: relevance of financial inclusion for developing nations. International Journal of Engineering and Science, 2(6), 15-20.

Tamilrasu, A. (2014). Role of banking sectors on financial inclusion development in India. International Interdisciplinary Research Journal, 2(2), 39-45. 